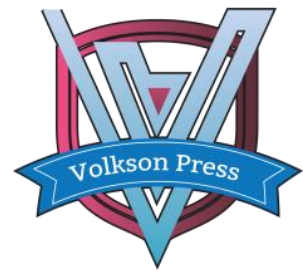

Contents List available at VOLKSON PRESS

Economics \& Management Innovations(EMI)

DOI : http://doi.org/10.26480/icemi.01.2017.421.422

\title{
Research on Entrepreneurship Psychology of College Students under the Background of Electronic Commerce
}

\author{
Li-na Xiao", ${ }^{\text {*, }}$ Yan-ze Yang ${ }^{2}$, Jing Lin ${ }^{1}$ \\ ${ }^{1}$ School of Management, Wuhan Donghu University, Wuhan, China \\ *email: 570993150@qq.com \\ This is an open access article distributed under the Creative Commons Attribution License, which permits unrestricted use, distribution, and reproduction in any \\ medium, provided the original work is properly cited.
}

\section{ARTICLE DETAILS}

\section{Article History:}

Received 02 october 2017

Accepted 06 october 2017

Available online 11 october 2017

Keywords:

E-commerce; College students;

Entrepreneurial psychology;

Quality; $\quad$ Suggestions.

\section{ABSTRACT}

In the context of high social concern for college students, entrepreneurship psychology has become one of the hot topics of social concern. Today, with the booming development of Taobao, Jingdong and other electronic commerce enterprises, e-commerce has become a major platform for the entrepreneurship of many college students. This document mainly analyzes the entrepreneurial psychology quality of college students', and discusses the problems of college students' entrepreneurial psychology in the background of e-commerce. Finally, it puts forward some suggestions on how to cultivate college students' entrepreneurial psychology quality.

\section{Introduction}

In recent years, with the transformation of China's development and increasing pressure on employment, entrepreneurship has become a career choice for university students and graduate students. By the end of 2016, six million personal shops has established through Taobao. Ecommerce has used its natural advantages directly or indirectly to create more than ten million jobs, but due to the lack of practical experience and ability, the entrepreneurial failure rate of college is rather high, so the concern about college students' entrepreneurial psychology is quite necessary.

Entrepreneurship psychology refers to the individual psychological characteristics that regulate the entrepreneurial practice in the process of entrepreneurship. Under the influence of this psychological adjustment, the entrepreneur will act as a driving force in the future development process and constantly firm up his goals in a difficult environment. Good entrepreneurial psychology will be expressed as self-confidence, optimism, independence, etc., playing an important role in the entrepreneurial activities.

\section{The formation of entrepreneurial psychological quality of college students}

Through the collection of related literature and interviews with some successful college students, the current psychological qualities of college students should include the following aspects:

\subsection{Confidence and self-control}

Self-confidence is the driving force of entrepreneurship. After college students rationally choose their entrepreneurial goals, they must be full of confidence in themselves, believing that they have the ability to overcome all difficulties to achieve the scheduled business goals. And good selfcontrol ability is the foundation of entrepreneurial success, so college students should be good at adjusting emotions, always keeping a cool head and firming entrepreneurial beliefs.

\subsection{High teamwork spirit}

In the early stage of entrepreneurship, it is very important to play the spirit of teamwork. In the road of entrepreneurship, college students need to have the quality of leading a team, a clear division of the team and cohesive team strength; so that they can work hard together to get through the bottleneck of entrepreneurship.

\subsection{Adventurous spirit and creative consciousness}

The entrepreneurship process is full of unknown and a variety of risks, so college entrepreneurs are expected to take risk, and they should have initiative spirit. In the process of entrepreneurship they will encounter many fierce competitions, so if they want to stand out, they must make full use of various resources and make bold innovation.

\subsection{Optimism}

Entrepreneurship is a long and tortuous process. The college students have to maintain an optimistic attitude, withstand all kinds of pressure, bear negative emotions, undergo disciplines and challenges and at last strengthen the road of entrepreneurship.

3. The psychological problems in college students entrepreneurship under the background of E-commerce

With the development of e-commerce, more and more college students choose to start their own businesses on the Internet. However, quite a few students suffer from various failures in the process of entrepreneurship. As for the problems of entrepreneurship, there are:

\subsection{Lack of concentration and patience}

Compared with the traditional business model, network business is facing the smaller pressure of funds, shops, personnel and other aspects, so in the start-up period, college students are often full of passion. They work very patiently, highly focused, and find ways to solve all the problems in entrepreneurship. But later, with the passage of time, the road of entrepreneurship will come to a bottleneck, and at this time, many business students will become restless and anxious, lack a comprehensive analysis of the network entrepreneurial projects, and therefore become no longer down-to-earth. If things go on like this, the shop operating would face difficulties and capital cutoff, leading to the failure of business.

\subsection{Self-confidence is impaired because the difference between reality and ideality}

In the early days of entrepreneurship, college students tend to have 
greater expectations for the future and are more concerned with initial earnings results and ignore future inputs. More college students are the first venture and lack of experience and ability; they are subject to interpersonal relationships and business network constraints and their ability to predict the risk is not enough, so ultimately, the actual situation can not achieve their desired results, which strike their self-confidence and makes them lose hope for the future.

\subsection{The restrictions of their own ability and the financial aspects}

Many college students have an average family economic status, so the problem of capital turnover and capital breakage hinders the pace of entrepreneurship. At the same time, the own cultural levels and personal accomplishments of the college students are also different in that the entrepreneurship itself is a highly practical project, so it is far from enough to rely solely on what is learned in schools.

\subsection{The personality of an entrepreneur}

Entrepreneurship is a long-term job, which requires good psychological quality. Some college students are at low self-esteem. They feel timid, worry about personal gains and losses and dare not to be bold. In addition, their mood swings quite larger. They are not able to handle themselves well when facing temptations, and a little success will make them be arrogant and pretentious. These personality problems will also affect the success of college students.

4. Suggestions on the cultivation of college students' entrepreneurial psychological quality under the background of e-commerce

Entrepreneurial psychology is an important prerequisite and condition for the success of college students. Entrepreneurial psychology can be cultivated from the society, university, family and college students themselves.

\subsection{Building a favorable social environment}

First of all, the state and governments at all levels should continue to vigorously foster the independent entrepreneurship programs of college students, continue to promote the legislative process, standardize the market economy environment in order to help students carry out their own business. For example, Wuhan launched the plan of "million students stay in Wuhan" and so on. Secondly, as for the tax incentives, credit guarantees, bank financing and so on aspects, the relevant government departments should also play an active role for college students, provide policy support for the graduate enterprise programs, reduce the financial pressure in the venture and raise the amount of loans, etc, which makes college students feel the government's attention and support for entrepreneurship and promotes college students to be optimistic, positive and courage to develop their own business.

\subsection{Strengthen the school's entrepreneurship education}

First of all, setting up the related courses of entrepreneurial theory to cultivate students' entrepreneurial theory and good psychological quality, which will lay a good foundation for students to start a business. Secondly, strengthening entrepreneurship practice education. The universities are supposed to construct the practice base of entrepreneurship, which will provide convenience for students' entrepreneurship practice, such as entrepreneurship training base, entrepreneurial practice base and Pioneer Park, so as to realize the integration of production, learning and research; Universities should also formulate a series of preferential policies for entrepreneurship, providing students with entrepreneurial sites, and look for and providing financial support; Universities also should hold more kinds of innovation and entrepreneurship competitions, such as "E-commerce Innovation, Creativity and Entrepreneurship Competition " to broaden the horizons of college students and cultivate their entrepreneurial interest.

\subsection{Strong support from the family}

The attitudes and opinions of family members about entrepreneurship will have a direct impact on the correct entrepreneurial psychology of college students. First of all, because the cost of electricity business is lower than the physical store and it is not subject to geographical constraints, so strengthening family communication can get emotional support as well as more social resources support; Secondly, in a family where conditions permit, supporting entrepreneurship means the economic help, which will help college students to tide over financial difficulties; Thirdly, entrepreneurship is a job with long incubation, so the time support of family can help students solve various problems in life and maintain a high degree of patience in the aspect of time, so that they can focus their attention on the entrepreneurship.

\subsection{Learning to adjust themselves}

First of all, college students need to cultivate a good entrepreneurial mentality, always keep calm and have a right understanding of entrepreneurship. Entrepreneurship is not limited to a good idea or originality, but also includes management, marketing, finance, manpower, cost budget and all aspects. Secondly, entrepreneurship is a kind of spirit, and college students should set up the correct concept of entrepreneurship and be optimistic to face challenges. In terms of ecommerce, although the difference in the capitalized cost of Taobao shops and physical shops is very different, their operating model is similar. College students should have certain plans for several elements the ecommerce and firm their own business aims.

\section{Conclusions}

In summary, entrepreneurship is both an opportunity and a challenge. Entrepreneurial psychological quality is an important psychological basis for college students' successful entrepreneurship. And the cultivation of entrepreneurial psychological quality requires the joint efforts of the government, universities, families and college students themselves.

\section{Acknowledgement}

This work was supported by the grants from Hubei Provincial Collaborative Innovation Centre of Agricultural E-Commerce (under Construction ) (Wuhan Donghu university research [2015] No. 11 Document)

\section{References}

[1] Liang Qiyu. Study on Entrepreneurship Education of College Students Based on E-commerce Platform [J]. Intelligence, 2017 (11).

[2] Wei Ran. Research on Problems and Countermeasures of College Students' Entrepreneurship. Journal of Jiamusi Vocational College, 2017 (1): 24-25.

[3] Luo Xiaodong, Liu Xiaomei, Liang Yuqing. Effects of E-commerce on Entrepreneurship Education of College Students [J]. Reform and Opening, 2017 (4): 82-83.

[4] Chen Hui. Study on the Influence of Family Background and Prospective Personality on College Students' Entrepreneurship Worship [D]. University of Science \& Technology of China, 2012.

[5] Lv Lian. Preliminary Study on Entrepreneurship of College Students in E-commerce [J]. Computer and telecommunications, 2015 (12): 23-26.

[6] Sun Fei-fei. Study on the Entrepreneurship Psychology of College Students - As an Example in the Ordinary Colleges [J]. Industry and Technology Forum, 2016, 15 (19): 117-118.

[7] Han Yu, Ning Yunxia. Study on the Countermeasures of Enhancing College Students' Psychological Wishes of Entrepreneurship [J]. Shanxi Youth, 2015 (23). 